\title{
Diálogos entre Paulo Freire e a Teologia da Libertação
}

Dialogues between Paulo Freire and Liberation Theology

\section{Carlos César de Oliveira carlosoliveira.prof@gmail.com}

Doutorando em Educação pelo Programa de Pós-Graduação em Educação (PPGE PUC Rio).

\section{Resumo}

Produzido a partir de uma revisão de literatura, o presente estudo discute as aproximações entre Paulo Freire e a Teologia da Libertação, possibilitando um (re)encontro com Dom Paulo Evaristo Arns. Assim, ao analisar as categorias "libertação", "participação" e "humanização", conclui-se que o "testemunho" dos "dois Paulos" - na educação e na pastoral - soa como convite a reinventá-los pelo diálogo, pensamento crítico e participação cidadã.

Palavras-chave: Paulo Freire; educação humanizadora; Teologia da Libertação; Dom Paulo Evaristo Arns; pastoral libertadora.

\begin{abstract}
This study, produced from a literature review, aims to discuss the approaches between Paulo Freire and Liberation Theology, enabling a (re)meeting with Dom Paulo Evaristo Arns. Thus, when analyzing the categories "liberation", "participation" and "humanization", it is concluded that the "testimony" of the "two Paulos" - in education and pastoral care - sounds like an invitation to reinvent them through dialogue, critical thinking and citizen participation. Keywords: Paulo Freire; humanizing education; Liberation Theology; Dom Paulo Evaristo Arns; liberating pastoral
\end{abstract}




\section{Aproximações entre a Educação e a Teologia: primeiras palavras}

A presença dos oprimidos na luta pela libertação será o que deve ser: não uma pseudoparticipação, mas sim uma ação comprometida.

Paulo Freire

O presente estudo é fruto de uma interlocução teórico-prática, visto que conjuga revisão bibliográfica e experiências vivenciadas pelo autor, tanto no campo da educação como na ação pastoral. Parto da premissa de que "os estudos de revisão consistem em organizar, esclarecer e resumir as principais obras existentes, bem como fornecer citações completas abrangendo o espectro de literatura relevante em uma área". Além disso, eles "podem apresentar uma revisão para fornecer um panorama histórico sobre um tema ou assunto considerando as publicações em um campo" (Vousgerau; Romanowski, 2014, p.167).

Neste sentido, ao cotejar aproximações entre a educação e a teologia, a revisão bibliográfica contribuiu para discutir o conceito "libertação", que serve como base tanto para o pensamento freiriano, com sua pedagogia libertadora, crítica, problematizadora da realidade (Freire, 1987), como para a concepção de pastoral libertadora (Libanio, 1986), que tem a Teologia da Libertação (TL) como fundamento. Com isso, este estudo almeja revisitar as bases do pensamento freiriano e da Teologia da Libertação, a fim de promover um (re)encontro com Dom Paulo Evaristo Arns e sua pastoralidade.

Porém, antes de qualquer indagação, cumpre dizer que este texto ganha forma a partir do olhar para a minha trajetória formativa (no âmbito da pastoral libertadora), e da percepção que o pensamento de Paulo Freire e a Teologia da Libertação trouxeram grandes contribuições para a minha vida: como sujeito e como cidadão. É voltando-me para esta encruzilhada que apresento a seguinte questão: em quais aspectos o pensamento de Paulo Freire dialoga com a Teologia da Libertação? A partir disso, busco compreender melhor o conceito de libertação, presente tanto em Freire como nos teólogos, bem como nas práticas de grupos católicos progressistas. Começo a problematizá-lo com base nos meus achismos, na minha curiosidade, afinal, durante as experiências pastorais, a vivência na Igreja, o conceito de "libertação" estava sempre presente. E não se tratava de uma "libertação do espírito" apenas, como evoca a concepção de "pastoral tradicionalista" (Libanio, 1986), mas uma libertação que envolve as questões do cotidiano, como, por exemplo, as desigualdades sociais, resultantes do modelo de sociedade classista. 
Assim, com as inquietações, meus "cirandeios" (Oliveira, 2020), foi possível constatar que o tema da libertação atravessa várias discussões no âmbito da Igreja católica (Libanio, 1986; Scannone, 1984; Medelín, 1968; Puebla, 1979) e da educação (Freire, 1978; 1979; 1981; 1987; 2007; Freire; Guimarães, 2011). Diante disso, busco problematizar a libertação partindo da premissa que "é um conceito central do pensamento freiriano, intrinsecamente vinculado à liberdade, conscientização e revolução" (Jones, 2016, p.243). Mas, e quanto à concepção de pastoral libertadora? O que podemos depreender dela? Com vista nas questões apresentadas e no diálogo aqui proposto, buscarei aprofundá-la no decorrer do texto, organizado em cinco momentos: inicialmente, justifico o porquê do tema, prosseguindo com uma discussão acerca da intrínseca relação entre libertação e participação. No terceiro e quarto momentos, me volto para o (re)encontro com Paulo Freire e Dom Paulo Evaristo Arns, atentando para a libertação (ou as lutas por ela) na América Latina, e para a importância das pessoas e de suas experiências para uma ação coletiva e solidária. Por fim, deixo um convite a nos inspirarmos no testemunho dos dois Paulos, e a darmos continuidade à defesa da vida e à superação das injustiças e desigualdades sociais

\section{É possível libertar-se sem participação?}

Para princípio de conversa, recorro à epígrafe inicial a fim de problematizar os conceitos libertação/participação. Afinal, quando Freire $(1979 ; 1987)$ afirma que a luta pela libertação implica numa "ação comprometida", ele nos instiga a pensar que a participação ativa, crítica, é um caminho imprescindível para transformação da realidade, graças ao engajamento, ao diálogo e à troca de saberes que dela decorrem. Com isso, o processo de libertação dos oprimidos torna-se fruto da sua participação, pois, através dela, eles começam a se (re)conhecer como sujeitos. Daí o caráter formativo do engajamento e da participação, pois, na medida em que se envolvem na ação e refletem sobre ela, acabam desenvolvendo uma consciência crítica acerca do seu papel sociedade. Esta é, portanto, uma das aproximações, isto é, um dos diálogos entre Paulo Freire e a Teologia da Libertação.

Vale lembrar que Pedagogia do Oprimido, de Paulo Freire, foi escrito em 1968, período em que a Teologia da Libertação germinava no chão latino-americano, e no mesmo ano em que aconteceu a Conferência Episcopal Latino-Americana de Medellín, na Colômbia. Naquele contexto, a opressão se dava de várias formas, seja pela desigualdade social, pela fome, pelos altos índices de analfabetismo seja pelos regimes ditatoriais que imperavam em vários países latino-americanos. Diante disso, a libertação se apresenta como um caminho 
necessário, pois para se libertar das amarras do opressor, ou, como diz Freire, para se desgarrar do opressor introjetado em nós, nas nossas ações, é preciso "ressuscitar" (Freire; Shor, 1986). Há que se revestir do "homem novo", ou seja, deixar morrer o opressor que existe dentro de si para dar vida a um ser crítico, participativo, ao cidadão. Nesta época, podemos identificar vários nomes, profetas e profetizas, porém, chamo atenção para D. Paulo Evaristo Arns, neste ano do seu centenário de nascimento, assunto que retomarei nos momentos que se seguem.

Pensando a questão da participação, e, mais ainda, da participação como instrumento de formação, de construção do pensamento crítico, debrucei-me sobre algumas obras de Paulo Freire com a finalidade de investigar e analisar a categoria "libertação". No entanto, quero ressaltar que, ao investigar a categoria libertação, atentei para outras categorias da mesma família semântica, como "libertador/a", "liberdade" ou "libertar", que são encontradas com frequência em sua obra, conforme destaco no quadro que se segue:

Quadro 1 - Análise do conceito (categoria) libertação em Paulo Freire

\begin{tabular}{|l|c|c|c|c|c|}
\hline \multicolumn{1}{|c|}{ OBRA } & $\begin{array}{c}\text { ANO } \\
\text { PUBLICAÇÃO }\end{array}$ & LIBERTAÇÃO & LIBERTADOR/A & LIBERDADE & LIBERTAR \\
\hline Educação como prática da liberdade & 1967 & 15 & 1 & 35 & 1 \\
\hline Pedagogia do Oprimido & 1968 & 86 & 47 & 85 & 14 \\
\hline Ação cultural para a liberdade & 1975 & 86 & 15 & 9 & 5 \\
\hline Conscientização & 1979 & 32 & 10 & 37 & 4 \\
\hline Educação e Mudança & 1979 & 5 & 2 & 5 & 1 \\
\hline Profes sora sim, tia não & 1993 & 0 & 0 & 59 & 0 \\
\hline Pedagogia da Autonomia & 1996 & 1 & 1 & 73 & 0 \\
\hline TOTAL DE REFER̂̂NCIAS & & $\mathbf{2 2 5}$ & $\mathbf{7 6}$ & $\mathbf{3 0 3}$ & $\mathbf{2 5}$ \\
\hline
\end{tabular}

Fonte: Elaboração própria, 2019.

Apoiado neste quadro, construído a partir de uma busca ${ }^{1}$ nas obras acima referenciadas, constato que o conceito de "libertação" é bastante recorrente no pensamento freiriano, sobretudo se analisarmos as obras publicadas entre o final dos anos 1960 e os anos 1970, quando do exílio de Paulo Freire (1964-1980). Partindo dessa premissa, afirmo que tanto o campo da educação como o da teologia libertadora surgiram em meio a uma realidade marcada por conflitos, opressão e exclusão das classes populares. Daí a sua intencionalidade de desenvolver práticas educativas (entendo a prática pastoral, nesse contexto, como uma

1 Busca realizada em obras digitalizadas (Adobe Reader - PDF). Caminhos da busca: Editar >>Localizar >>Abrir pasta total do Reader ou (Atalho: Ctrl+F e Shift+Ctrl+F), seguindo-se da Especificação da palavra que deseja pesquisar >> Pesquisar. 
prática educativa) pautadas na ideia de conscientização dos sujeitos e de participação popular. Isto é, uma prática educativa que seja capaz de trabalhar a formação, tomando como base a realidade do indivíduo e a sua classe social.

Foi em meio a esse contexto que Paulo Freire tratou de uma pedagogia "do oprimido", e não "para o oprimido". Ao mesmo tempo, propôs uma ação educativa que fosse capaz de desenvolver a sua capacidade crítica, a ponto de abandonar a sua condição de objeto e assumir sua condição de sujeito transformador da sua realidade. Assim, fundamentada na práxis, a conscientização se dá a partir do momento em que os sujeitos, por meio da participação e do engajamento, "tomam posse da realidade" (Freire, 1979, p.16).

\title{
A América Latina e as lutas pela libertação: um (re)encontro com Paulo Freire e Dom Paulo Evaristo Arns
}

\begin{abstract}
Embora eu não seja um teólogo, alinho-me àqueles que consideram que a teologia tem um papel importante a desempenhar.
\end{abstract}

Paulo Freire

Quanto às referências diretas feitas por Freire à TL, destaco que as identifiquei em Ação Cultural para a Liberdade, Conscientização: teoria e prática da libertação, Política e Educação, Os cristãos e a libertação dos oprimidos, Tecer mundo y teología. Carta a um joven teólogo e em Aprendendo com a própria história. Nesta última, fruto do seu diálogo com Guimarães (2011), o autor fala da sua amizade e dos seus encontros com teólogos da libertação, entre eles Gustavo Gutierrez, considerado o precursor da TL na América Latina. Além disso, quando da sua atuação no Conselho Mundial das Igrejas, Freire destacou que a Teologia da Libertação não aconteceu "somente no campo católico, mas também no campo protestante" (Freire; Guimarães, 2011, p.174), algo que, muitas vezes, passa despercebido.

Após fazer uma breve explanação acerca da Teologia da Libertação, Freire afirmou: "há uma indiscutível relação entre mim e a Teologia da Libertação" e completou dizendo: "gostaria de insistir, que talvez eles tenham me influenciado mais do que eu a eles" (Freire; Guimarães, 2011, p.174). Assim, reconhecendo a proximidade entre a Teologia da Libertação e a Educação Libertadora, Freire certa vez concluiu:

pra mim é uma razão de alegria, e de muita responsabilidade, reconhecer que, mesmo sem ser teólogo, fui influenciado, tive uma influência nesse 
movimento de educação e libertação que é a Teologia da Libertação. (Freire; Guimarães, 2011, p.173).

Nas citações em destaque, o próprio Freire analisa a sua relação com a TL, o que, de certo modo, vem corroborar com a discussão suscitada por este estudo (ver quadro acima) acerca da recorrência da "libertação" nas suas produções escritas até o final da década de 1970, especialmente em Pedagogia do oprimido (1987) e em Ação cultural para a liberdade (1981).

Uma outra aproximação entre a Pedagogia Libertadora e a Teologia da Libertação está relacionada às questões de identidade e classes sociais. Ambas reconhecem a necessidade de problematizar a realidade, o contexto social, de maneira que os oprimidos - por meio do engajamento e da participação - possam se conscientizar da importância do seu papel ativo na construção de um modelo de sociedade a partir dos oprimidos, isto é, por meio de uma democracia popular. Todavia, em função da discussão sobre classe, tanto o campo da educação quanto algumas “vertentes” da Teologia da Libertação (Scannone, 1984) serão alvos de crítica por parte de setores católicos e da sociedade civil.

Para Freire "é impossível mudar as pessoas sem mudar a realidade concreta" (1974 - a tradução é própria). Na sua Carta a um jovem teólogo (1974), o autor chama a atenção para a relação entre o ser humano e a realidade, apontando a necessidade de levar em consideração o contexto em que as pessoas estão inseridas, isto é, o seu aspecto social, cultural, econômico e político. Por meio dessa afirmação, atento para a relação entre as pessoas e a realidade concreta, busco ampliar esta discussão, tratando da relação pessoas-igreja-sociedade como uma relação dialética, por meio da qual as pessoas compreendem o seu papel no mundo e, à medida que agem nele, se formam ao transformar a realidade.

É neste contexto, nesta relação homem-igreja-sociedade, que, por exemplo, encontrarmos Dom Paulo Evaristo Arns, com uma atuação pastoral engajada, comprometida com a transformação social, seja por meio das Comunidades Eclesiais de Base, seja por sua atuação com os mais pobres e periféricos, na sua constante luta em defesa da pessoa humana (Arns, 2001). Afinal, a luta em defesa das pessoas oprimidas, dos excluídos da sociedade, dos Direitos Humanos e contra a ditadura militar foram algumas marcas da sua pastoralidade. Com isso, a proposta educativa de Freire dialoga com o modelo de pastoralidade adotado por Arns.

Dito isso, trago para a discussão uma categoria marcante no pensamento freiriano: o testemunho. Associado a uma atitude ético-estética com a sociedade, por exemplo, o 
testemunho é mediado pela práxis (ação-reflexão), pela denúncia e pelo anúncio. Com relação a isto, pode-se dizer que Paulo Freire e D. Paulo Evaristo Arns viveram os seus testemunhos, seja na educação, seja na pastoral. Com relação a Arns, observa-se que anunciou o evangelho, denunciou as mazelas sociais e posicionou-se contra o regime militar instaurado no Brasil em 1964, regime este que levou Freire ao exílio por quase 16 anos. Ambos deram o seu testemunho na ação concreta, na relação homem-mundo, jamais assumindo uma atitude fatalista ante a realidade. Assim, ao refletir e intervir na história para transformá-la, fizeram história, inclusive na PUC-SP, visto que Paulo Freire fora convidado por D. Paulo Evaristo Arns para lá lecionar. Enfim, fizeram história, aprenderam com ela e escreveram sobre ela.

\section{As pessoas como ponto de partida para uma ação coletiva e um quefazer solidário}

Freire associa o conceito de libertação à humanização ${ }^{2}$, e adverte que, em uma sociedade classista, se não lutamos contra as desigualdades (sociais, econômicas, culturais), é em vão falarmos de humanização. Assim, tanto a humanização como a libertação só acontecerão à medida em que as classes populares se reconhecem enquanto parte responsável pela transformação da sociedade. Sobre esse assunto, é importante dizer que por meio da educação humanizadora (crítico-dialógica) o sujeito se liberta de pensamentos e atitudes desumanas, conforme asseverou Freire (1987). Isso significa dizer que a ação/educação humanizadora implica, antes de mais nada, na capacidade de enxergar as pessoas oprimidas como seres de direitos e de se posicionar diante da negação, do apagamento e exclusão, a exemplo do que fizeram Freire e Arns. Como já citei, ambos deram os seus testemunhos ético e estético - ao dedicarem suas vidas a uma ação educativa (compreendendo, também, a ação pastoral como educativa) que tem como fundamento o respeito às diferenças, o cuidado, a solidariedade, o diálogo e o acolhimento, a fim de que as pessoas despertem o "ser mais" (Freire, 1987) que existe nelas, muitas vezes vilipendiado pelas formas de opressão e de exclusão social. Assim, diante da ação/educação humanizada, o sujeito passa a compreender seu papel na sociedade, uma vez que o pensamento crítico o leva a romper com as formas de opressão e de desumanização que o afligem. Portanto, enquanto construção histórica, inconclusa, a humanização implica em um processo que se dá ao longo da vida, a partir dos

\footnotetext{
2 Sobre este assunto, ver "Algumas notas sobre humanização e suas implicações pedagógicas", no livro Ação cultural para a liberdade, de Paulo Freire (1981), bem como a categoria Humanização/Desumanização no Dicionário Paulo Freire (Streck et al., 2016).
} 
diálogos e das relações socioculturais tecidas entre/com pessoas, por meio das quais é possível chegar à condição de sujeitos autônomos e cidadãos, capazes de intervir no mundo.

Um outro aspecto ao qual quero chamar atenção diz respeito ao caráter polissêmico da libertação no âmbito da Igreja Católica. Se a analisarmos a partir do Documento de Puebla (1979), por exemplo, notaremos que é empregada inúmeras vezes ${ }^{3}$. Todavia, Freire nos lembra que a "verdadeira libertação" e o "autêntico processo de libertação" (Freire, 1981) se darão por meio da práxis, ou seja, por meio da "reflexão e ação dos homens no mundo para transformá-lo" (Freire, 1987, p.21). Ressalto que a concepção apresentada por Freire pode ser associada, por exemplo, ao aspecto profético, observado no trabalho pastoral desenvolvido pelo Cardeal Arns, conforme afirmou Dom Angélico Sândalo Bernardino:

Ele é ecumênico, coração aberto, anunciando a urgência de resistirmos contra toda mentira, contra toda impostura. Naquele tempo, contra a ditadura civil-militar. E essa resistência, a que ele nos convida, é permanente no Brasil atual. (MORAES, 2016, n.p.).

Ou seja, a libertação se pauta na ideia da denúncia e do anúncio, na ação com o povo, no processo de conscientização, de modo que, ao superarem as situações de opressão e o silenciamento que delas decorrem, as pessoas assumam o seu papel como cidadãs.

Em face disso, considero que em algumas “correntes" da TL (Scannone, 1984) a compreensão de libertação irá se assemelhar ao pensamento freiriano, especialmente se compararmos o conceito de práxis com o método "ver-julgar-agir", que implica neste olhar para a realidade (ver) a fim de refletir sobre ela, de problematizá-la (julgar), para então encontrar caminhos para a ação (agir). Com isso, a libertação pode ser compreendida como um processo de evangelização que leva em consideração o engajamento e a construção de um pensamento crítico a serviço das lutas e da superação das desigualdades sociais.

Entretanto, esta compreensão acerca da libertação será alvo de muitas críticas por parte da Igreja. Afinal, cada concepção de pastoral (Libanio, 1986), ou seja, cada modelo de Igreja, vai conceituar a libertação de uma forma distinta. A pastoral clássica, por exemplo, pautandose numa visão transcendentalizada, pregará a libertação apenas do ponto de vista espiritual, isto é, livre do pecado e esquecendo-se das relações sociais, opressoras e desiguais que

\footnotetext{
${ }^{3}$ Ao analisar a categoria "libertação", no primeiro momento fiz uma comparação entre Puebla (1979) e Medellín (1968). Diante disso, identifiquei que em Medellín ela é usada 24 vezes e, em Puebla, 222 vezes. Tal comparação pode apontar que, com a efervescência da Teologia da Libertação no final dos anos 1960 e durante a década de 1970, a categoria "libertação" resultou em disputas conceituais em Puebla, o que se justifica pelo emprego de "libertação integral", de modo que a questão de "classe" fica subentendida.
} 
afligem a sociedade. Um dos aspectos que diferencia a concepção clássica da libertadora é que, enquanto a libertadora volta o seu olhar também para as questões político-sociais, para o cotidiano, a clássica rejeita esta relação entre a religião e a política. Já no âmbito da pastoral moderna, recorro ao documento de Puebla ${ }^{4}$ (1979) que, numa espécie de ressignificação do conceito de libertação, parece procurar distanciá-lo do profético (anúncio e denúncia) pregado por alguns teólogos da libertação, associando-o a uma "verdadeira libertação" ou "libertação integral". Neste contexto, o termo assume uma conotação que remete mais à questão do pecado e à ideia de salvação, deixando as questões sociais em segundo plano.

Posicionando-se contrário às concepções clássicas e modernizantes, Freire afirma que

Quanto mais envolvidos estivermos nas formas de ação baseadas na ilusão idealista, tanto mais estamos ao serviço das elites de poder e assim nossa ação se torna necessariamente paternalista. Em vez de trabalhar para transformar a realidade injusta cooperamos em "assistencialismos" e atividades que eu normalmente chamo de "fornecer aspirinas". Precisamente em razão deste tipo de atividade, as elites proclamam nossa virtude, enquanto nós continuamos dormindo em paz. (Freire, 1974, - grifo do autor - a tradução é própria)

E conclui:

Uma teologia em que a esperança fosse uma espera sem busca, seria profundamente alienante, porque compreende o homem como alguém que renunciou à sua práxis no mundo; negaria o homem como um ser em transformação e também negaria sua própria salvação como uma busca da conversão. (FREIRE, 1974 - a tradução é própria)

Para o autor, uma teologia que dorme em paz, que desenvolve a sua ação na perspectiva de uma esperança ingênua - que nada mais é do que uma pura espera - que não luta pela transformação da sociedade, é uma teologia defensora da manutenção e da continuidade das desigualdades sociais. É uma teologia que teme a mudança, prioriza a transmissão do conhecimento e o distanciamento do povo, ao invés do diálogo. Algo que também pode ser aplicado ao campo da educação. O pensamento de Freire nos instiga, ainda, a refletir sobre a nossa ação. Afinal, o modelo de pastoral, de educação, de sociedade que defendemos está a

\footnotetext{
${ }^{4}$ Nos vários momentos em que é empregada, a libertação é apresentada como: i) "autêntica libertação do homem"; ii) "comunhão e participação para autêntica libertação"; iii) "libertação do pecado"; iv) "libertação integral" da opressão e do pecado, na dimensão terrena e dimensão espiritual; v) "verdadeira libertação"; vi) "evangelho da libertação"; vii) "a evangelização articulada com a defesa dos direitos humanos e com a libertação" (CELAM, 1979).
} 
serviço de quem? E quanto às práticas, qual o seu compromisso com a libertação? E em mais uma de suas referências à TL, Freire assevera que

\begin{abstract}
as fontes da Teologia da Libertação, como todo mundo sabe, ultrapassam de longe as contribuições que venho tentando dar no campo da educação para a libertação. Mas também não tenho dúvida de que, neste ou naquele momento, nesta ou naquela visão da prática pedagógica, e na questão da natureza política do ato educativo, que venho sublinhando com tanta ênfase desde os anos de 1960, em tudo isso certamente há algo que tem a ver com a Teologia da Libertação, da mesma forma que ela tem algo a ver com a minha de compreender a educação e a libertação também. (Freire; Guimarães, 2011, p.173).
\end{abstract}

A citação em destaque, além de ratificar a relação entre a Teologia da Libertação e a Educação Libertadora, vem reforçar que tanto uma quanto a outra compreendem a natureza política do ato educativo, da participação e do diálogo como caminhos formativos. Por esse motivo, é importante frisar que em ambos os casos a ação tem como ponto de partida a realidade dos sujeitos, o contexto em que vivem, a sua vivência cultural, a comunhão e a solidariedade (troca de saberes, ajuda mútua) entre as pessoas. Logo, ao problematizar a realidade, refletir sobre a prática e analisar as suas relações com o mundo, estamos nos aproximando do que o autor chamou de "natureza política do ato educativo".

E, dentro deste contexto, a cultura e os saberes dela provenientes assumem um papel fundamental, pois além de mostrarem que os seres humanos não são "vazios", reforçam a importância do diálogo acerca das experiências de vida, algo extremamente formativo, tendo em vista a capacidade que temos em aprender com a própria história (Freire; Guimarães, 2011). Assim, tanto a pedagogia crítica, libertadora (Paulo Freire) como a ação pastoral, humanizadora (Dom Paulo Evaristo Arns) são instrumentos a serviço da libertação. E ambas encontram, nos elementos da cultura e na ação com o povo, caminhos e possibilidades para trabalhar a formação de homens e mulheres a partir da sua experiência de mundo, reconhecendo que neste "ato de educar" (Freire, 1987), de participar, ensinamos e aprendemos coletivamente.

\title{
Um convite para reinventar a ação humanizadora dos "dois Paulos"
}

Por tudo o que foi apresentado, chego ao final deste estudo com maior clareza acerca dos diálogos entre Paulo Freire e a Teologia da Libertação. Afinal, durante a minha trajetória formativa - sobretudo no âmbito pastoral - passei a indagar estas possíveis aproximações 
entre Freire e os teólogos com os quais dialogávamos. Um outro aspecto diz respeito ao testemunho, tão presente em Freire e em Arns, resultando neste (re)encontro e, ao mesmo tempo, neste diálogo entre mim e eles. A partir deles escrevo, dialogo, exercito a práxis. Por isso não apresento considerações, mas sim um convite para darmos continuidade ao testemunho de vida e de luta experienciado por ambos. E chego ao final deste texto ciente de que, à medida que escrevo e reflito, passo a melhor compreender o papel da libertação, no seu sentido crítico, participativo, transformador, tanto no âmbito teológico-pastoral como no educacional.

Acentuo, porém, que o olhar problematizador acerca das questões de classe, das questões políticas e o fato de estar ao lado do povo e com ele continua a ser questionado pelos modelos de Igreja Tradicional e parte da Igreja Moderna, que o associam ao comunismo, ao socialismo e ao marxismo, sem nenhuma ou com pouca profundidade acerca desses temas. São falas que, embora se digam neutras - pois "não se envolvem com política", e a libertação, na sua visão, se dá apenas no plano espiritual - estão carregadas da ideologia dominante, logo classista, em defesa de um status quo e da manutenção das relações de poder. Sobre este assunto, temos muito o que aprender com os testemunhos de Paulo Freire e Dom Paulo Evaristo Arns.

Por fim, considero que os encontros, os diálogos, a seriedade e o testemunho na luta contra as injustiças (Freire, 1987) possibilitam-nos criar uma ação comprometida com os oprimidos e oprimidas, de modo a contribuir com a tomada de consciência e, por conseguinte, a superação das desigualdades. Assim, entendendo que o testemunho e o diálogo são elementos fundantes do ato educativo e do fazer pastoral, os diálogos aqui tecidos, além de possibilitarem (re)encontros com a TL e com os dois Paulos, dois homens de fé - em Deus e nas pessoas -, fazem ecoar um convite à esperança. Não a esperança da pura espera, apocalíptica, mas a esperança transformadora, ação no mundo, isto é, um "esperançar" (Freire, 1987) feito com o povo, a partir das classes populares. Seguir o testemunho é, ao mesmo tempo, convite e caminho para mantermos vivas suas memórias, e suas lutas. Por isso, escrever, esperançar, lutar, viver, transformar e libertar são verbos (ação) que fazem: Paulo Freire (1921-1997), presente! Dom Paulo Evaristo Arns (1921-2016), presente! 


\section{Referências bibliográficas}

ARNS, Paulo Evaristo. Da esperança à utopia: Testemunho de uma vida. Rio de Janeiro: Sextante, 2001.

CELAM. Documento de Medellín: sobre a presença da Igreja na atual transformação da América Latina à luz do Concílio Vaticano II. Colômbia, 1968. Disponível em: $<$ https://www.faculdadejesuita.edu.br/eventodinamico/eventos/documentos/documentoFwdDtt9v3ukKPDZq.pdf $>$. Acesso em : 5 out 2020.

CELAM. Documento de Puebla: sobre a evangelização e no presente e no futuro da América Latina. México: 1979. Disponível em: < http://portal.pucminas.br/imagedb/documento/DOC_DSC_NOME_ARQUI20130906182452. pdf>. Acesso em: 12 set 2020.

FREIRE, Paulo. Ação Cultural para a Liberdade. 5.ed. São Paulo: Paz e Terra, 1981.

FREIRE, Paulo. Conscientização: teoria e prática da libertação. São Paulo: Cortez \& Moraes, 1979.

FREIRE, Paulo. Educação como prática da liberdade. Rio de Janeiro: Paz e Terra, 1967.

FREIRE, Paulo. Os cristãos e a libertação dos oprimidos. Porto: Edições Base, 1978.

FREIRE, Paulo. Pedagogia do Oprimido. 17.ed. Rio de Janeiro: Paz e Terra, 1987.

FREIRE, Paulo. Política e Educação. 8.ed. Indaiatuba: Vila da Letras, 2007.

FREIRE, Paulo. Tercer mundo y teología: Carta a un joven teólogo. Revista Selecciones de Teología, v.13, n.50, abr/jun 1974. Disponível em:

<http://www.seleccionesdeteologia.net/selecciones/llib/vol13/50/050_freire.pdf>. Acesso: 4 nov 2020.

FREIRE, Paulo; GUIMARÃES, Sérgio. Aprendendo com a própria história. São Paulo: Paz e Terra, 2011.

FREIRE, Paulo; SHOR, Ira. Medo e Ousadia: O Cotidiano do Professor. Trad. Adriana Lopez; rev. tec. Lólio Lourenço de Oliveira. Rio de Janeiro: Paz e Terra, 1986. Educação e Comunicação, v.18.

JONES, Lauren Ila. Libertação. In: STRECK, Danilo R: REDIN, Euclides; ZITKOSKI, Jaime José (orgs). Dicionário Paulo Freire. 3.ed. Belo Horizonte: Autêntica, 2016, p. 243-244.

LIBANIO, João Batista. O que é pastoral. 3.ed. São Paulo: Brasiliense, 1986. Primeiros Passos, 69.

MORAES, Camila. Morre Dom Paulo Evaristo Arns, "o cardeal da esperança". El País, São Paulo edição 14 dez 2016. Disponível em: 
https://brasil.elpais.com/brasil/2016/12/13/politica/1481637238_864951.html. Acesso: 12 set 2020.

SCANNONE, Juan Carlos. La Teología de la Liberación: Caracterización, corrientes, etapas. Revista Selecciones de Teología, v.23, n.92, out/dez 1984. Disponível em:

$\langle$ http://seleccionesdeteologia.net/selecciones/llib/vol23/92/092_scannone.pdf〉. Acesso: 10 jan 2021.

STRECK, D. R.; REDIN, E.; ZITKOSKI, J. J (orgs). Dicionário Paulo Freire. 2.ed. Belo Horizonte: Autêntica, 2016.

VOSGERAU, Dilmeire Sant'Anna Ramos; ROMANOWSKI, Joana Paulin. Estudos de revisão: implicações conceituais e metodológicas. Diálogo Educacional, Curitiba, v.14, n.41, p.165-189, jan/abr 2014. 